\title{
Erratum to: Role of central and peripheral opioid receptors in the cardioprotection of intravenous morphine preconditioning
}

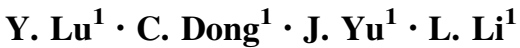

Published online: 18 December 2015

(C) Royal Academy of Medicine in Ireland 2015

\section{Erratum to: Ir J Med Sci (2011) 180:881-885 DOI 10.1007/s11845-011-0734-0}

The authors would like to publish an erratum to correct the errors in "Abstract" and "Materials and methods" section. The respective corrected paragraphs are given below (emphasis added to corrected text).

Corrected Abstract:

Methods Sixty-five anesthetized, open chests, male Sprague-Dawley rats were assigned to one of nine groups after intrathecal catheter placement. IPC was induced by three cycles of intermittent occlusion of left anterior descending artery (5 min occlusion interspersed with $5 \mathrm{~min}$ of reperfusion). MPC was induced by three consecutive intravenous infusions of $100 \mu \mathrm{g} / \mathrm{kg}$ morphine over $5 \mathrm{~min}$. The opioid receptors antagonist naloxone methiodide (NM), was intravenously or intrathecally, at a dose of $20 \mathrm{mg} / \mathbf{k g}$ or $20 \mu \mathrm{g} / \mathrm{kg}$, given $10 \mathrm{~min}$ before IPC or MPC (IVN$\mathrm{M}+$ IPC, ITNM + IPC, IVNM + MPC, ITNM + MPC). Control group $(\mathrm{CON})$ and intravenously or intrathecally administered NM (IVNM, ITNM) were used as negative controls, respectively. All hearts were subjected to $30 \mathrm{~min}$ of ischemia follow by $2 \mathrm{~h}$ of reperfusion. Infarct size, as a percentage of the area at risk, was determined by 2, 3,

The online version of the original article can be found under doi:10.1007/s11845-011-0734-0.

Y. Lu

luyao-mz@163.com

1 Department of Anaesthesiology, Third Affiliated Hospital of Anhui Medical University, Hefei 230061, China 5-triphenyltetrazolium staining. Heart rate and mean arterial blood pressure were monitored.

Corrected Materials and methods:

Study groups and experiments protocol

Rats were randomly assigned to receive one of nine treatments (Fig. 1). All animals were subjected to $30 \mathrm{~min}$ of ischemia by occlusion of the left anterior descending artery followed by $2 \mathrm{~h}$ of reperfusion by release of the occlusion: 1. CON, rats were induced by $30 \mathrm{~min}$ ischemia and $2 \mathrm{~h}$ reperfusion; 2. IPC, before the $30 \mathrm{~min}$ ischemia of the left anterior descending artery, rats were subjected to preconditioning by ischemia (IPC, 3 cycles of $5 \mathrm{~min}$ ischemia and 5 min reperfusion); 3. MPC, MPC hearts were subjected to three 5 min cycles of intravenous morphine at $100 \mu \mathrm{g} / \mathrm{kg}$ interspersed with $5 \mathrm{~min}$ drug-free periods prior to sustained ischemia; 4. IVNM + IPC, naloxone methiodide (NM) $20 \mathrm{mg} / \mathrm{kg}$ i.v. $10 \mathrm{~min}$ before IPC; 5. ITNM + IPC, naloxone methiodide (NM) $20 \mu \mathrm{g} / \mathrm{kg}$ i.t. $10 \mathrm{~min}$ before IPC; 6. IVNM + MPC naloxone methiodide (NM) $20 \mathrm{mg} /$ kg i.v. 10 min before MPC; 7. ITNM + MPC, naloxone methiodide (NM) $20 \mu \mathrm{g} / \mathrm{kg}$ i.t. $10 \mathrm{~min}$ before MPC; 8 . IVNM, naloxone methiodide (NM) $20 \mathrm{mg} / \mathrm{kg}$ i.v. $40 \mathrm{~min}$ before ischemia; 9. ITNM, naloxone methiodide (NM) $20 \mu \mathrm{g} / \mathrm{kg}$ i.t. $40 \mathrm{~min}$ before ischemia. 